\title{
The Study on Lightning Disaster Risk Assessment Model of 10kV Overhead Line
}

\author{
Song wei ${ }^{1, \text { a }}$, Wang Yanfeng ${ }^{2, \mathrm{~b}}$, Wang shuanghu ${ }^{3, \mathrm{c}}$ \\ ${ }^{1}$ NARI Group CorporationNanjing 210061, China 86-025-81089152 \\ ${ }^{2}$ NARI Group CorporationNanjing 210061, China 86-025-81089152 \\ ${ }^{3}$ NARI Group Corporation Nanjing 210061, China 86-025-81089152
}

\begin{abstract}
Taking all kinds of affecting factors into account, the $10 \mathrm{kV}$ overhead line of distribution network lighting disaster risk is studied. Historical hidden fault, line equipment, topography, climatic conditions and social impact are selected as key factors of damage and the impact. The correlation among the factors and the weight ratio of each factor were studied. The risk assessment model of $10 \mathrm{kV}$ distribution network overhead line was established by multi-factor, hierarchical classification assessment method. It solves the evaluation index insufficient problem of the single factor as the evaluation condition, and provides the theoretical research and practical support to the $10 \mathrm{kV}$ overhead line reconstruction and the lightning prevention. The reliability and effectiveness of the research results have been proved by practical application in distribution network operation and maintenance control.
\end{abstract}

CCS Concepts

- Applied computing $\rightarrow$ Electronic commerce $\rightarrow$ Electronic data interchange.

\section{INTRODUCTION}

With the rapid development of power system and the increasing level of management, distribution network management and safe operation work has been attached great importance, as directly to the power users to allocate electrical power network configuration, the efficiency of its operation directly affects the overall economic efficiency of the grid operation, So its safety and reliability more and more attention [1]. Lightning disasters as an unavoidable external disaster, to the safe operation of the grid has brought a lot of risk.

At present, there are few researches on the safety risk of lightning damage. In 1992, the US Electric Power Research Institute EPRI released a direct use of the US national lightning monitoring data for lightning protection overhead transmission line lightning performance simulation platform [2]. In 2006, the International Electrotechnical Commission (IEC) and the International Telecommunication Union (ITU) and other organizations to develop a lightning disaster risk assessment IEC61662 [3]. In 2007, China's North China Electric Power Research Institute and State Grid Power Research Institute for the first time put forward the lightning distribution map, and developed the relevant lightning protection standards [4].

Lightning has a high over-voltage amplitude, a shorter discharge time, insulated wire insulation layer can be high-voltage breakdown, causing the insulator flashover, at the same time, the frequency of freewheeling caused by air ionization [5-7].

\section{MODEL STRUCTURE}

$10 \mathrm{kV}$ distribution network overhead lines in different areas of the line, the same line of different line sections, different towers suffered lightning characteristics vary, different lines of lightning strike on the power grid of the different risks, the same line in the determination of time and mode of operation under the lightning strike The risk of distribution network is not the same, need to carry out overhead lines to carry out multi-factor lightning damage assessment work by section of mine thinking to carry out the deployment of overhead lines lightning protection work.

By dividing the tower and the tower section of the distribution grid overhead line, each base tower is regarded as the basic unit of the risk assessment of the lightning hazard, and the lightning hazard state of each tower is calculated on a grid-by-base basis. Then, the risk assessment status of the whole line of the aerial line of the distribution line is evaluated. The hierarchical evaluation system of the tower and the tower section to the distribution network overhead line is put forward, Risk assessment, the model structure shown in Figure 1.

\footnotetext{
* Corresponding author: ${ }^{\text {ahuadiansongwei@ } 163 . c o m . c n}{ }^{\mathrm{b}}$ wangyanfeng@ sgepri.sgcc.com.cn

${ }^{\mathrm{c}}$ wangshuanghu@sgepri.sgcc.com.cn
} 


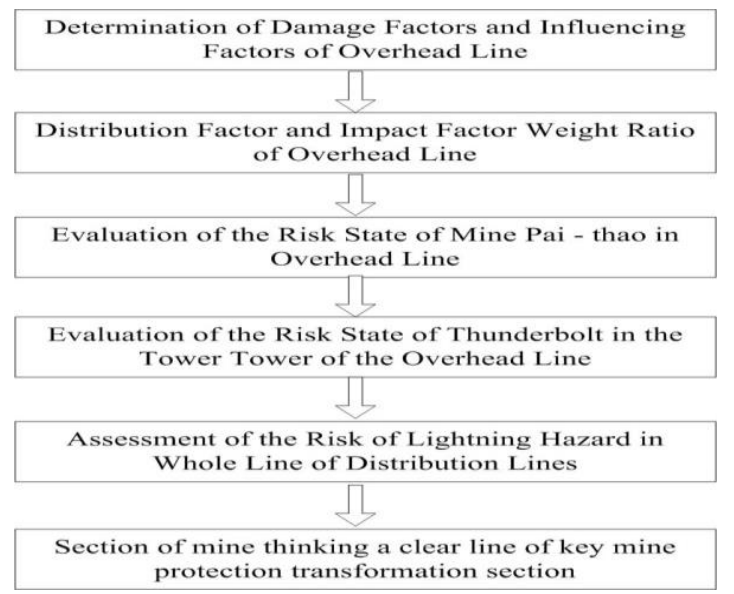

Figure 1. Structure of light hazard assessment model for $10 \mathrm{kV}$ overhead line in distribution network

\section{ASSESSMENT ANALYSIS}

\subsection{Hidden Trouble}

Analysis of the distribution network overhead lines roadbed tower lightning failures in nearly three years history, there are obvious fault points, wire break, the porcelain lightning damaged, arrester lightning damage, transformer lightning damage. Such failure points increase the probability of the hazard of the tower. According to the number of lightning strike failures in the last three years, the points are deducted. The more the deduction, the more the number of lightning strikes, the greater the risk. The scoring rules are like tables 1 .

Table 1. Scoring according to lightning strike times of towers

\begin{tabular}{lc}
\hline $\begin{array}{l}\text { Lightning strike times of towers in } \\
\text { nearly three years }\end{array}$ & Scores \\
\hline 1 time & 3 \\
2 times & 6 \\
3 times & 9 \\
4 times & 12 \\
Over 5 times & 15
\end{tabular}

In the past three years, the two base towers of the base tower of the network overhead column have been broken. There are obvious fault points, wire break, the porcelain lightning damaged, arrester Lightning damage, transformer lightning damage. Such failure points increase the probability of the hazard of the tower. According to the number of lightning strike failures in the last three years, the points are deducted. The more the deduction, the more the number of lightning strikes, the greater the risk. The scoring rules are like tables 2 .

Table 2. Scoring according to lightning strike times of before and after the base towers

\begin{tabular}{lc}
\hline $\begin{array}{l}\text { Lightning strike times of towers in } \\
\text { nearly three years }\end{array}$ & Scores \\
\hline $1-2$ times & 1.5 \\
$3-5$ times & 3 \\
\hline
\end{tabular}

\section{Over 6 times} 6

In the last three years, an analysis of the network overhead circuit has occurred but there is no point of apparent failure, recombination success, check the line no abnormality. According to the number of times to deduct points, deducting more risk is bigger, the scoring rules are like tables 3 .

Table 3. Scoring according to the lightning outage times but no fault point

\begin{tabular}{lc}
\hline $\begin{array}{l}\text { Lightning outage times } \\
\text { in nearly three years }\end{array}$ & Scores \\
\hline 1-5 times & 1.5 \\
6-10 times & 3 \\
Over 10 times & 5 \\
\hline
\end{tabular}

Analysis of overhead lines of distribution network line $1 \mathrm{kM}$ in nearly three years the number of lightning, the whole line $1 \mathrm{kM}$ line will increase the risk of lightning flash. The whole line 1KM in lightning frequency points more, more deduction of points. The scoring rules are like tables 4.

Table 4. Scoring according to lightning frequency of $1 \mathrm{KM}$ line

\begin{tabular}{lc}
\hline $\begin{array}{l}\text { The number of lightning times in } \\
\text { nearly three years }\end{array}$ & Scores \\
\hline $1-20$ times & 1 \\
21-40 times & 2 \\
$41-60$ times & 3 \\
61-80 times & 4 \\
Over 80 times & 6 \\
\hline
\end{tabular}

\subsection{Line Equipment}

Analyze the type and working life of the insulators of overhead transmission lines in distribution network, and deduct the points according to the type and operation period. The scoring rules are like tables 5 .

Table5. Scoring according to insulator type and running time

\begin{tabular}{lllll}
\hline Type of insulator & Scores & Running time & Scor \\
\hline
\end{tabular}




\begin{tabular}{lllc}
\hline & & of insulator & es \\
\hline Pin InsulatorP-6T & 6 & $1-5$ years & 1 \\
Pin InsulatorP-10T & 4 & 6-10 years & 2 \\
Pin InsulatorP-15T & 3 & $11-15$ years & 3 \\
Pin InsulatorP-20T & 2 & $16-20$ years & 4 \\
Pillar InsulatorPS-20 & 1 & Over 20 years & 6
\end{tabular}

The type and working life of lightning arrester of overhead transmission line foundation tower in distribution network are analyzed, and points are deducted according to type and operation period. The scoring rules are like tables 6 .

Table6. Scoring according to arrester type and running time

\begin{tabular}{|c|c|c|c|}
\hline Type of arrester & Scores & $\begin{array}{l}\text { Running } \\
\text { time } \\
\text { arrester }\end{array}$ & Scores \\
\hline $\begin{array}{l}\text { Arrester no } \\
\text { installed(no } \\
\text { transformer, } \\
\text { column switch } \\
\text { and cable on the } \\
\text { tower) }\end{array}$ & 1 & $6-10$ years & 3 \\
\hline $\begin{array}{l}\text { Arrester not with } \\
\text { out series gap (no } \\
\text { transformer, } \\
\text { column switch } \\
\text { and cable on the } \\
\text { tower) }\end{array}$ & 0.5 & 11-15years & 4 \\
\hline $\begin{array}{l}\text { Arrester not with } \\
\text { series gap } \\
\text { (transformer, } \\
\text { column switch } \\
\text { and cable on the } \\
\text { tower) }\end{array}$ & 2 & $\begin{array}{l}\text { Over } \\
\text { years }\end{array}$ & 6 \\
\hline
\end{tabular}

Analysis of overhead lines of distribution network a base tower grounding resistance, lightning current need to discharge through the earth, the grounding resistance is directly related to the size and risk of lightning. The scoring rules are like tables 7 .

Table 7. Scoring according to tower grounding resistance

\begin{tabular}{llll}
\hline $\begin{array}{l}\text { Installation } \\
\text { 100kVA and } \\
\text { above } \\
\text { distribution } \\
\text { transformer }\end{array}$ & Scores & $\begin{array}{l}\text { No distribution } \\
\text { transformer in } \\
\text { tower }\end{array}$ & Scores \\
\hline $4-10 \Omega$ & 1 & $10-15 \Omega$ & 1 \\
$11-15 \Omega$ & 2 & $16-20 \Omega$ & 2 \\
$16-20 \Omega$ & 3 & $21-25 \Omega$ & 3 \\
Above $20 \Omega$ & 5 & Above $25 \Omega$ & 5 \\
\hline
\end{tabular}

The analysis between the two pole span length of overhead lines of distribution network, two tower space is too long will lead to increased risk of lightning conductor section, will increase the conductor mechanical stress when lightning prone to wire break fault, according to the two points between the span length of the tower. The scoring rules are like tables 8 .
Table 8. Scoring according to span length

\begin{tabular}{lc}
\hline Span length & Scores \\
\hline $70-100$ meters & 1 \\
$100-150$ meters & 2 \\
$150-200$ meters & 3 \\
Over 200 meters & 5
\end{tabular}

Analysis of cable type of overhead lines of distribution network and operation period, when the overhead conductors for bare wire, with the increasing running time overhead conductor rain erosion and contamination, surface oxidation resistance of oxide layer is serious, great value, will increase the risk of bare wire lightning, scoring according to the type and operation life of overhead conductors. The scoring rules are like tables 9.

Table9. Scoring according to cable type and running time

\begin{tabular}{llll}
\hline $\begin{array}{l}\text { Overhead bare } \\
\text { cable }\end{array}$ & Scores & $\begin{array}{l}\text { Overhead } \\
\text { insulated cable }\end{array}$ & Scores \\
\hline 2-5 years & 2 & 3-5 years & 1 \\
6-10 years & 3 & 6-10 years & 2 \\
11-15 years & 4 & 11-15 years & 3 \\
15-20 years & 5 & 15-20 years & 4 \\
Over20 years & 7 & Over 20 years & 6
\end{tabular}

Analysis of crossing overhead lines of distribution network, when there is a line between two towers of overhead lines of distribution network and other overhead line crossing, due to attack or shielding factors caused by the overhead lines of distribution network lightning, so the selection of overhead lines of distribution network crossing as virulence factor, and points according to different voltage level. The scoring rules are like tables 10.

Table 10. Scoring according to crossing overhead lines

\begin{tabular}{lcc}
\hline $\begin{array}{l}\text { Voltage grade } \\
\text { overhead lines }\end{array}$ & of crossing & Scores \\
\hline $10 \mathrm{kV}$ & 1 \\
$35 \mathrm{kV}$ & 2 \\
$110 \mathrm{kV}$ & 3 \\
Over $220 \mathrm{kV}$ & 5 \\
\hline
\end{tabular}

\subsection{Topographic Features}

Analysis of overhead lines of distribution network of a base tower where topography, different topography will affect the lightning risk value, set the corresponding score according to the different landform. The scoring rules are like tables 11 .

Table 11. Scoring according to topography of the tower

\begin{tabular}{lc}
\hline Topography & Scores \\
\hline On mountain slope & 1 \\
In the valley & 1 \\
\hline
\end{tabular}




\begin{tabular}{ll}
\hline On the hillside & 2 \\
In the plain & 2 \\
Along the plain river & 3 \\
Across valleys & 3 \\
Top of the mountain & 4
\end{tabular}

It is easy to be struck by lightning when the basic tower of overhead distribution line is located above the average altitude of the line. Therefore, the average elevation of the tower is higher than the average altitude of the line, which is regarded as the damage factor. The scoring rules are like tables 12 .

Table12. Scoring according to above the average altitude of the line

\begin{tabular}{cc}
\hline Above the average altitude of the line & Scores \\
\hline 5-10 meters & 1 \\
10-20 meters & 2 \\
20-30 meters & 3 \\
30-40 meters & 4 \\
Over 40 meters & 5 \\
\hline
\end{tabular}

Study on the distribution of overhead line tower surrounding vegetation coverage, dense vegetation cover in line and tower, resulting in power distribution lines, flashover insulation damage, so the overhead lines of distribution network more dense vegetation coverage, the greater the possibility of the occurrence of lightning, so the selection of base tower vegetation coverage rate as a virulence factor. The scoring rules are like tables 13 .

Table 13. Scoring according to Vegetation coverage around the tower

\begin{tabular}{lc}
\hline Vegetation coverage & Scores \\
\hline $2-5 \%$ & 1 \\
$5-10 \%$ & 2 \\
$10-15 \%$ & 3 \\
$15-20 \%$ & 4 \\
Over 20\% & 6 \\
\hline
\end{tabular}

Analysis of the distribution network of overhead line tower two existed across the river or reservoir, across the river or reservoir will greatly increase the risk of lightning tower, so as to select the factors and factor. The scoring rules are like table 14 .

Table 14. Scoring according to towers across the river or reservoir

\begin{tabular}{lc}
\hline Across the river or reservoir & Scores \\
\hline Across the river & 2 \\
Across the reservoir & 3 \\
\hline
\end{tabular}

\subsection{Climatic Conditions}

This paper analyzes the whole line lightning density (Unit: sub / square kilometer / year) of overhead lines in distribution network, and the probability that lightning density directly influences the lightning stroke of overhead lines, and selects this factor as the cause of harm. The scoring rules are like table 15 .

Table 15. Scoring according to the whole line lightning density

\begin{tabular}{cc}
\hline $\begin{array}{l}\text { Lightning density } \\
\text { (sub / square kilometer / year })\end{array}$ & Scores \\
\hline $\mathrm{B} 1 \operatorname{grade}\left(0.78 \leq_{\mathrm{Ng}<2.0)}\right.$ & 1 \\
$\mathrm{~B} 2 \operatorname{grade}\left(2.0 \leq_{\mathrm{Ng}<2.78)}\right.$ & 2 \\
$\mathrm{C} 1 \operatorname{grade}\left(2.78 \leq_{\mathrm{Ng}<5.0)}\right.$ & 4 \\
$\mathrm{C} 2 \operatorname{grade}\left(5.0 \leq_{\mathrm{Ng}<7.98)}\right.$ & 5 \\
$\mathrm{D} 1 \operatorname{grade}\left(7.98 \leq_{\mathrm{Ng}<11.0)}\right.$ & 7 \\
$\mathrm{D} 2 \operatorname{grade}\left(\mathrm{Ng} \geq_{11.0)}\right.$ & 8
\end{tabular}

Analysis of overhead lines of distribution network line location of annual rainfall (Unit: $\mathrm{mm} /$ year), rainfall is the whole line locations for long-term humid regions, greater the rainfall, the possibility of lightning flashover lines is bigger, so the selection of factors for virulence factor. The scoring rules are like table 16.

Table16. Scoring according to annual rainfall

\begin{tabular}{cc}
\hline Annual rainfall (mm / year) & scores \\
\hline $400-500$ & 1 \\
$500-650$ & 2 \\
$650-800$ & 3 \\
$800-1000$ & 4 \\
Over 1000 & 6 \\
\hline
\end{tabular}

Analysis of overhead lines of distribution network line location for nearly three years, the maximum wind speed (Unit: Meters per second), due to wind induced convective clouds is a necessary condition for thunderstorms, pressure change can increase the thunderstorm weather risk, so choose this factor for virulence factor. The scoring rules are like table 17.

Table 17. Scoring according to the maximum wind speed

\begin{tabular}{lc}
\hline The maximum wind speed $(\mathbf{M} / \mathbf{s})$ & Scores \\
\hline $8-10$ & 1 \\
$10-13$ & 2 \\
$13-18$ & 3 \\
$18-23$ & 4 \\
Over 23 & 6 \\
\hline
\end{tabular}

\subsection{Social Influence}

Analysis of overhead lines of distribution network line power supply important grade and quantity of the lightning stroke fault trip will cause particularly important or important users of power interruption, thus selecting the factors influencing factor. 
Table 18. Scoring according to important grade and quantity of power consumers

\begin{tabular}{lcclc}
\hline $\begin{array}{l}\text { Number of } \\
\text { significant user }\end{array}$ & $\begin{array}{c}\text { Score } \\
\text { s }\end{array}$ & $\begin{array}{l}\text { Number of } \\
\text { important user }\end{array}$ & Scores \\
\hline 1 user & 2 & 1 user & 1 \\
2 users & 3 & $2-3$ users & 2 \\
3 users & 4 & $4-5$ users & 3 \\
4 users & 5 & More than 6 & 5 \\
$\begin{array}{l}\text { More than } \\
\text { users }\end{array}$ & 8 & users & & \\
\hline
\end{tabular}

Analyzes the frequency of complaints about service quality in the past three years. The more complaints, the greater the social pressure, and chooses this factor as the influencing factor. The scoring rules are like table 19.

Table 19. Scoring according to the frequency of complaints

\begin{tabular}{lc}
\hline Frequency of complaints & Scores \\
\hline 3 -5 times & 1 \\
6-10 times & 2 \\
$11-15$ times & 3 \\
$16-20$ times & 4 \\
Over 20 times & 6
\end{tabular}

Analysis of overhead lines of distribution network line for nearly a year the average load rate of lightning trip fault will cause loss of power supply load, causing economic losses, so the selection of factors influencing factor. The scoring rules are like table 20 .

Table 20. Scoring according to the average load rate

\begin{tabular}{cc}
\hline The average load rate & Scores \\
\hline $60 \%-65 \%$ & 1 \\
$65 \%-70 \%$ & 2 \\
$70 \%-75 \%$ & 3 \\
$75 \%-80 \%$ & 4 \\
Over $80 \%$ & 6 \\
\hline
\end{tabular}

\subsection{Summary}

From the above 5 aspects of problems, historical fault line equipment, topography, climate conditions and social impact from lightning damage caused by the key factor and the influence factor of 20 , with the $10 \mathrm{kV}$ overhead line as a unit, in accordance with the rules of scoring table, finally the cumulative score is high, then the overhead line lightning risk further, according to the score list to find the risk, make difference operation.

\section{CONCLUSION}

The $10 \mathrm{kV}$ overhead line lightning risk assessment model proposed in this paper has been applied in the distribution network of $10 \mathrm{kV}$ overhead line operation and maintenance, reducing the lightning events occurring in the process of distribution network operation and maintenance rate, improve the reliability and safety of power supply.

\section{ACKNOWLEDGMENTS}

The work was financially supported by project (524609170057,524608160065)

\section{Authors' background}

\begin{tabular}{|l|l|l|l|}
\hline Your Name & Title* & $\begin{array}{l}\text { Research } \\
\text { Field }\end{array}$ & $\begin{array}{l}\text { Personal } \\
\text { website }\end{array}$ \\
\hline Song wei & $\begin{array}{l}\text { Electrical } \\
\text { Engineer }\end{array}$ & $\begin{array}{l}\text { Distribution } \\
\text { network field }\end{array}$ & - \\
\hline Wang yanfeng & $\begin{array}{l}\text { Electrical } \\
\text { Engineer }\end{array}$ & $\begin{array}{l}\text { Distribution } \\
\text { network field }\end{array}$ & - \\
\hline $\begin{array}{l}\text { Wang } \\
\text { shuanghu }\end{array}$ & $\begin{array}{l}\text { Senior } \\
\text { Electrical } \\
\text { Engineer }\end{array}$ & $\begin{array}{l}\text { Distribution } \\
\text { network field }\end{array}$ & - \\
\hline
\end{tabular}

\section{REFERENCES}

1. Zhang zhiwei. Lightning protection measures of $10 \mathrm{kV}$ distribution line $[\mathrm{J}]$. Electric Power Standardization \& Construction Cost Control Information, 2016(3):48-49. (In Chinese)

2. Mc DermottTE, Longo VJ. Advanced computional methodsin lightning performance-The EPRI lightning protection designworstation.

3. [C]//Power Engineering Society Winter Meeting, Power Engineering Society, New York,USA: IEEE.IEC 62305-1.Protection against lightning-Partl: General-Principle,2006.

4. Cheng jiahong, Wang jian, and Tong xuefang,etc.Study on Lightning Distribution Grid[J].High Voltage Engineering,2008,34(10):2016-2021.(In Chinese)

5. Cheng shuiming and $\mathrm{He}$ jingliang.Method of preventing insulated conductor breakage of the distribution line $[\mathrm{C}]$ High Voltage Commission of CSEE (Chinese Society of Electrical Engineering) Academic Conference in 2004. (In Chinese)

6. Zhao Chun, Ruan Jiang Jun, Li Xiaolan, etc.Comprehensive transmission line lightning protection measures of technical and economic evaluation[J].High Voltage Engineering,2011(2):290297.(In Chinese)

7. Li Zhen, Yu Zhanqing, He Jinliang, et al.The analysis of lightning protection performance of tower multi circuit improved line arrester[J].High Voltage Engineering,2011(12):3120-3128. (In Chinese) 